\title{
"SISTEM MONITORING PRIVATE AUTOMATIC BRANCH EXCHANGE DENGAN TAMPILAN PERSONAL COMPUTER BERBASIS WIRELLESS "
}

\author{
Yuyun Suprapto ${ }^{1}$, Syamsul Maarif $^{2}$, Totok Warsito ${ }^{3}$, Eriyandi $^{4}$ \\ 1,2,3,4)Politeknik Penerbangan Surabaya \\ Jl. Jemur Andayani I, No. 73 Surabaya 60236 \\ Email : yuyunatkpsby@gmail.com
}

\begin{abstract}
:
The telephone is a communication tool that can connect someone with others quickly. Communication using the phone has become a primary need for the community, especially in large cities, agencies, to large enterprises. The phone service users in bulk urgently need a alatyang is the development of telephone communication tool known as the PABX (Private Automatic Branch Exchange).

In this study the author uses the theory of the resistors, capacitors, diodes LED, optocoupler, Pro wireless XBee, XBee Pro adapter, PABX theory, the theory of the phone, Atmega 16 microcontroller and programming languages. The method used in this research is to study literature, comparative studies of the lecturers, field studies and through experiments in the laboratory.

The conclusion of this design are the technicians who worked on the PABX unit can determine the condition of the telephone line clearly and be more efficient in monitoring the telephone line with a distance of affordable, especially if there is damage to phone lines can directly send on display Personal Computer.
\end{abstract}

Keyword : communication, Pro wireless, PABX unit

\section{LATAR BELAKANG}

Dunia informasi saat ini seakan tidak bisa terlepas dari teknologi. Telepon adalah suatu alat komunikasi yang dapat menghubungkan seseorang dengan orang lainnya secara cepat. Dibandingkan dengan menuliskan surat atau mengirimkan telegram, mengirimkan berita lewat telepon menjadi lebih cepat dan praktis. Dengan telepon seseorang dapat langsung saling berbagi cerita dengan orang lainnya.

Para pengguna layanan telephone dalam jumlah besar dalam suatu instansi, kantor, atau bahkan perusahaan besar sangat membutuhkan suatu alat yang merupakan pengembangan dari alat komunikasi telephone ini. Alat ini dikenal dengan nama PABX (Private Automatic Branch Exchange). Dalam penggunaan PABX (Private Automatic Branch Exchange) ini dalam kondisi saat ini. Dalam penggunaannya tidak dapat dihindari banyak sekali terjadi gangguan atau kerusakan yang diakibatkan oleh salah satu saluran dan kurang efisiensinya monitoring dari PABX tersebut atau bahkan dari telepon itu sendiri. Dari berbagai gangguan, kerusakan dan kurang praktisnya monitoring yang terjadi.

Dalam pembuatan alat pendeteksi saluran telephone pada PABX ini, penulis menggunakan tampilan berupa Personal Computer (PC) untuk mempermudah dan memberi keefisiensian kinerja para teknisi supaya para teknisi dapat lebih cepat dan mudah mengetahui kondisi saluran telephone pada PABX jika salah satu dari saluran tersebut mengalami kerusakan. “ Sistem Monitoring Private Automatic Branch Exchange dengan tampilan Personal Computer berbasis Wirelless".

\section{BENTUK PENELITIAN}

Hasil dari penelitian ini berupa sistem monitoring PABX dengan tampilan PC berbasis wireless. Diharapkan dengan adanya alat ini dapat memudahkan teknisi PABX untuk 
mengetahui kondisi saluran telepon dan telepon yang sedang digunakan melalui monitoring pada PC teknisi.

\section{RANCANGAN PENELITIAN}

Berdasarkan uraian di atas, sebuah rancangan yang bisa membantu kerja teknisi di ruangan $\mathrm{PABX}$ agar kondisi saluran telepon yang rusak ataupun yang sedang dalam posisi digunakan, atau terhubung, atau tidak terhubung dapat diketahui secara jelas. Berikut adalah gambar blok diagram kondisi yang diinginkan.

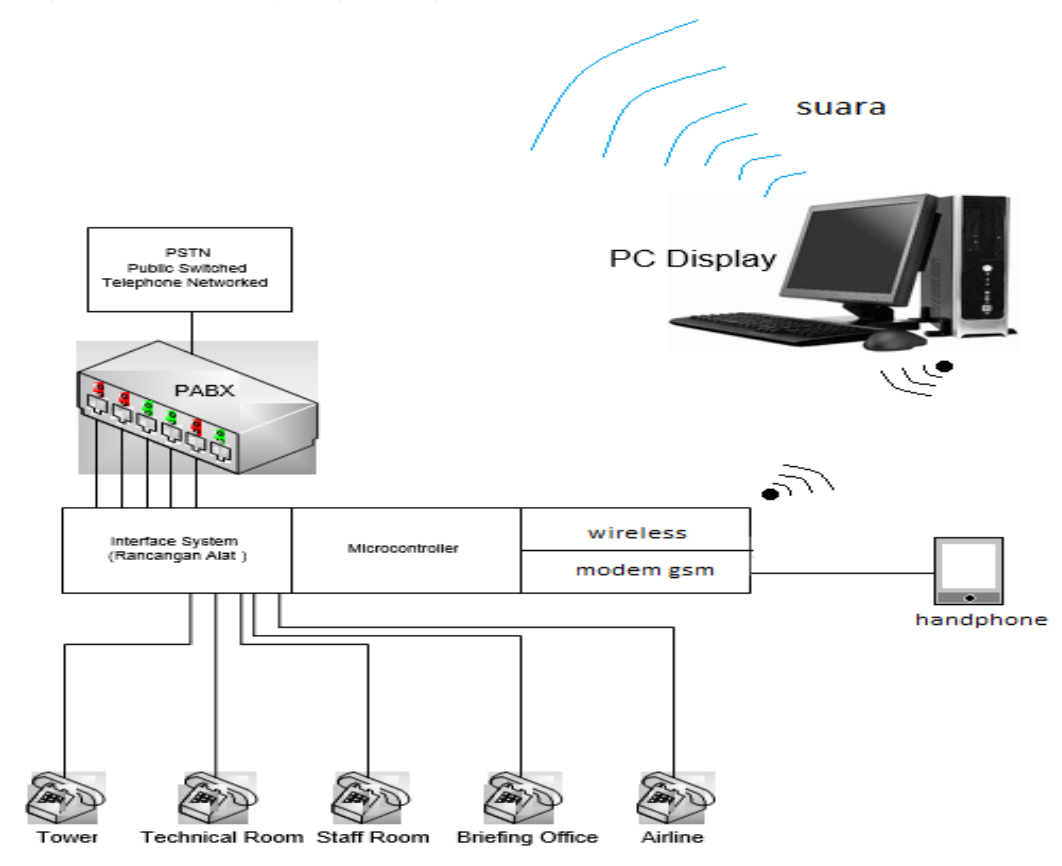

Gambar 1. Blok Diagram Rancangan

Dari gambar 1 di jelaskan bahwa alat pendeteksi saluran telephone pada PABX dapat di pasang sedemikian rupa sehingga untuk melakukan monitoring pada tiap-tiap saluran telephone yang tersebar di tiap-tiap ruangan dapat dilakukan dengan mudah apalagi jika disetiap ruangan tersedia PC maka akan lebih efesien lagi dalam memonitoringnya. Alat pendeteksi saluran telephone pada PABX ini dapat diletakkan bersama PABX nya pada ruang server. Dimana pada ruang server memiliki prinsip kerja sebagai center atau pusat dari seluruh telephone-telephone yang berada di tiap-tiap ruangan di suatu bangunan, gedung, kantor, atau bahkan perusahaan yang menggunakan pelayanan jasa telekomunikasi dengan PABX ini.

Cara kerja dari block diagram di atasakan dijelaskan pada penjelasan di bawah ini.

1. Pada PSTN (Public Switched Telephone Networked), PSTN merupakan contoh dari jaringan publik yang berarti jaringan telepon tetap yang menggunakan kabel sebagai perantara media penghubung. PSTN di block diagram di atas digunakan untuk penghubung jaringan agar masing-masing pesawat telepon bisa terhubung satu sama lain.

2. PABX (Private Automatic Branch Exchange) adalah pada dasarnya sebuah sistem telepon yang biasa disebut juga dengan switchboard yang digunakan sebagai sistem telepon internal kantor. Cara kerja PABX adalah bahwa sesungguhnya perangkat ini merupakan modem yang berfungsi sebagai control station pusat. Setiap kali ada telepon baru yang masuk, maka telepon tersebut akan di-routing (diarahkan) melalui control station ini. Karena di dalam sistem PABX tersebut telah dimasukkan kode tertentu untuk masingmasng nomor telepon di kantor, atau untuk masing-masing extension, maka telepon tersebut akan diarahkan ke tujuan yang tepat dengan menggunakan kode tersebut. 
3. Interface System (Rancangan Alat), Rancangan alat disini adalah hardware dari block diagram keseluruhan rancangan yang diinginkan, digunakan sebagai bagian yang dijalankan oleh microcontroller dari rancangan.
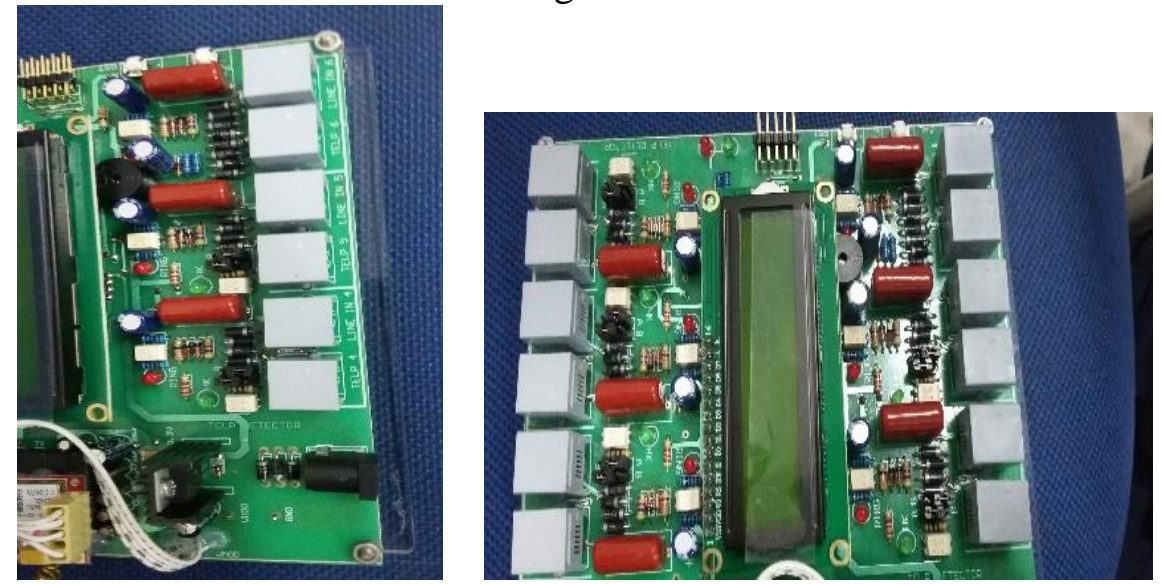

Gambar 2. Interface System (Rancangan Alat)

4. Microcontroller adalah suatu pusat dari hardware ini yang menjalankan Rancangan alat, digunakan sebagai otak dari rancangan keseluruhan alat. Pada rancangan ini menggunakan Atmega 16.

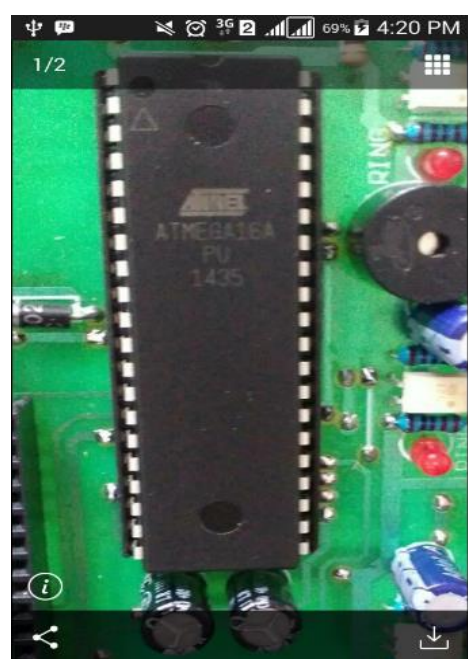

Gambar 3.. Microcontroller Atmega 16

5. Wireless adalah suatu perangkat yang pada rancangan alat ini berupa Xbee, yang digunakan untuk menghubungkan antara rancangan alat dengan PC server untuk tempat yang jauh yang masih terjangkau oleh Xbee itu sendiri.

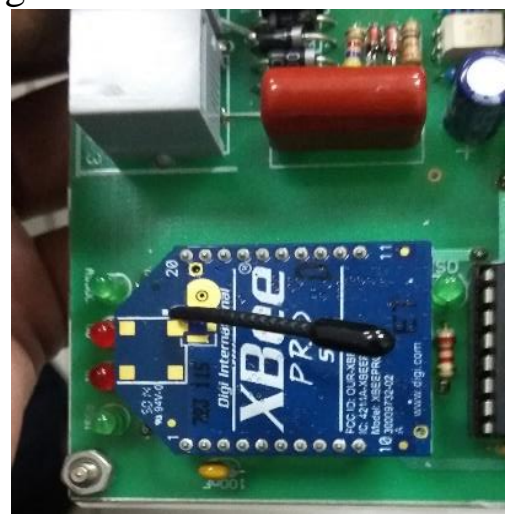

Gambar 4. Wireless (Xbee Pro) 
7. Pesawat telepon disini adalah sebuah kumpulan telepon yang terhubung masing-masing ke sebuah PABX dalam suatu gedung/ bandara. Pada rancangan block diagram di atas berfungsi sebagai benda yang dideteksi yakni berupa on hook, off hook, ringing, dan failure.

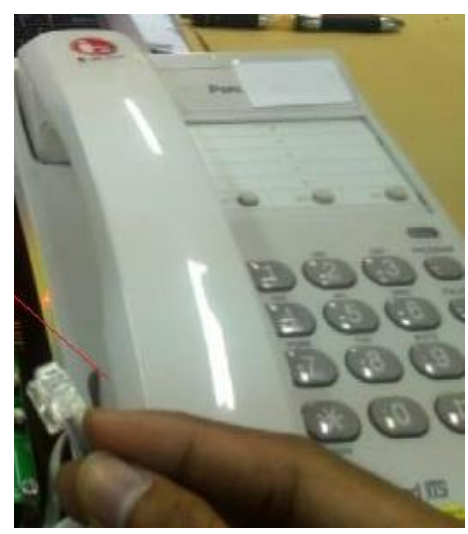

Gambar 5. Pesawat Telepon

8. PC Display adalah sebuah perangkat yang pada rancangan alat ini sebuah laptop, yang digunakan untuk perangkat yang memonitoring kondisi telepon yang dideteksi, dan juga bisa mengeluarkan keluaran suara untuk masing-masing kondisi yang muncul menggunakan software Visual Basic 2008 Express.

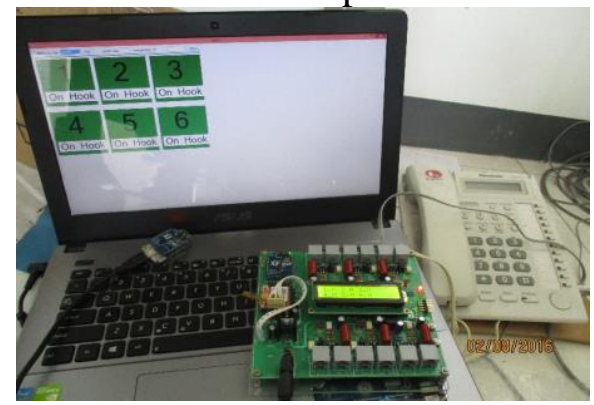

Gambar 6. PC Display

Cara kerja keseluruhan dari Block Diagram di atas dapat di simpulkan sebagai berikut. Pada block diagram diatas yang berperan penting untuk pengolahan data dan menjalankan program pada alat adalah Microcontroller sebagai pusat dari Rancangan alat. Pada block diagram diatas terdapat Interface System (Rancangan Alat), Microcontroller dan Wireless. Hardware alat ini menjadi satu kesatuan yang menjadi berupa rancangan alat yang akan dihubungkan ke PABX dan Pesawat telepon melalui kabel RJ11 guna untuk mendeteksi kondisi dari pesawat telepon yang akan dideteksi.

Untuk PABX sendiri harus sudah terhubung ke PSTN, agar bisa digunakan memonitoring kondisi pesawat telepon. Pada wireless ini ada 2, yakni berada pada pc dan rancangan alat agar kondisi dari pesawat telepon yang akan dideteksi bisa dimonitoring dengan pc melalui wireless ini yang dinamakan Xbee Pro. Setelah terhubung wireless antara PC dan rancangan alat maka tinggal pemrograman menggunakan Visual Basic 2008 Express sebagai monitoring pada PC. Jadi singkatnya, cara kerjanya adalah PSTN sebagai jaringan pada PABX agar pesawat telepon bisa terhubung satu sama lain. Kemudian PABX untuk menghubungkan banyak pesawat telepon jadi satu kesatuan dan bisa terhubung satu sama lain. Kemudian pada Hardware alat (Interface system, Microcontroller, Wireless) bekerja sebagai alat yang mendeteksi kondisi dari pesawat telepon yang mendapat sumber tegangan 12 Volt yang berupa adapter, kemudian akan dikirimkan pada PC melalui Xbee yang 
kemudian PC bertugas memonitoring kondisi pesawat telepon pada jarak yang jauh yang masih terjangkau.

\section{Bentuk Rancangan}

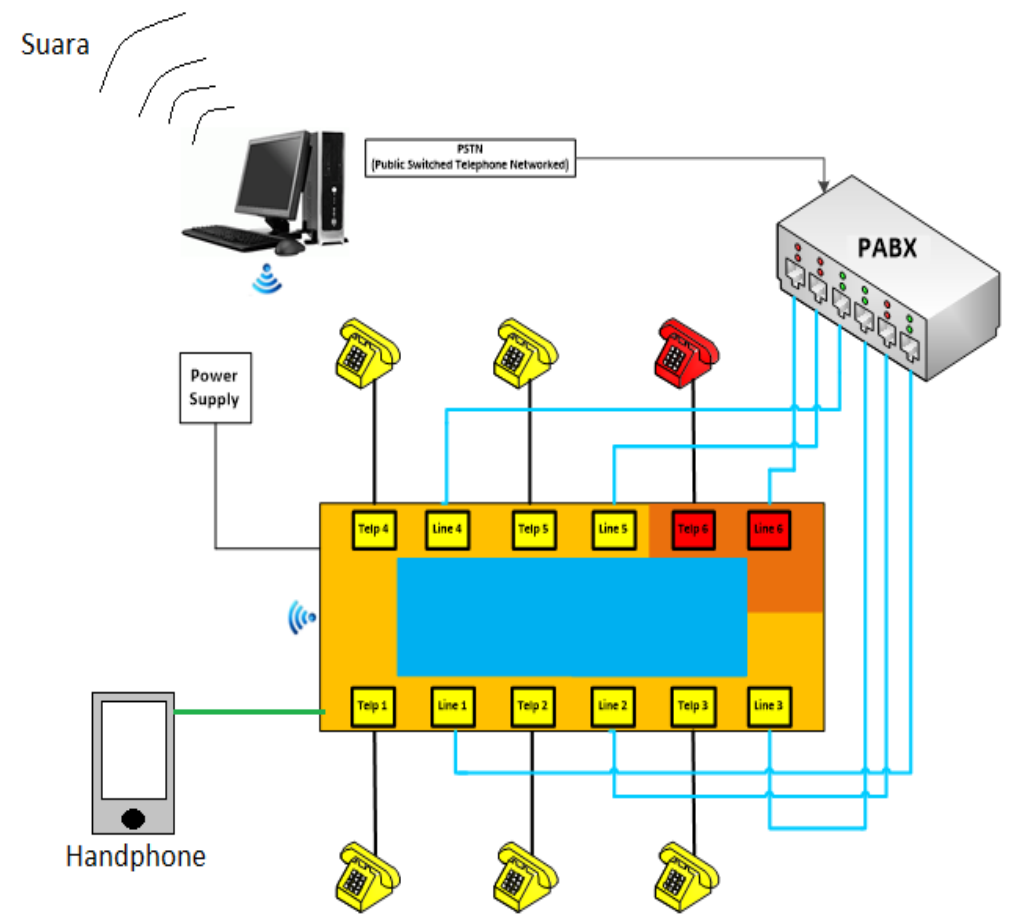

Gambar 7. Skema Rancangan

Keterangan :

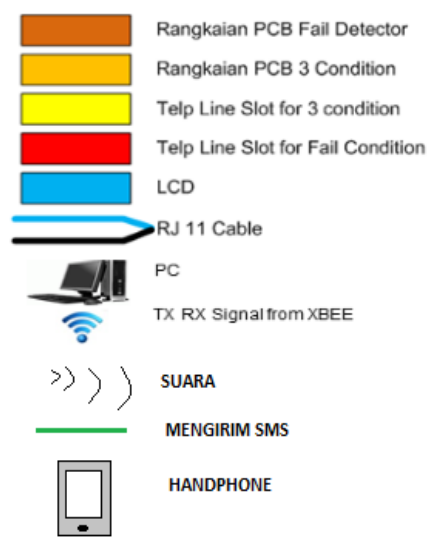

Pada Skema rancangan diatas dijelaskan bahwa terdapat rangkaian yang secara sistemnya terdapat dalam PCB. Ini dikarenakan Rangkaian digunakan untuk mendeteksi empat kondisi disetiap masing-masing yaitu On Hook, Off Hook, Ringing dan Failure.

Berikut ini akan diberikan contoh gambar rancangan gedung dengan menggunakan jasa layanan telekomunikasi PABX, yang mana dalam gambar tersebut akan diketahui posisiposisi telephone di setiap ruangan pada bangunan / gedung tersebut serta posisi ruang server atau center dari PABX dan alat pendeteksi saluran telephone pada PABX yang di buat oleh penulis. 

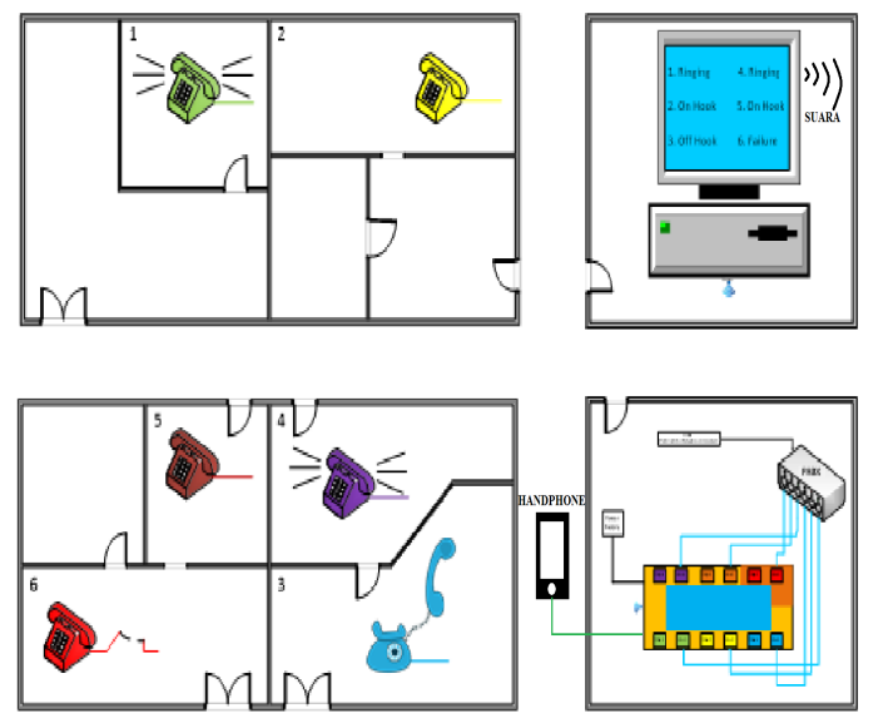

Gambar 8. Contoh ruangan server dan telephone setiap ruangan

\section{KONSEP RANCANGAN}

Dengan adanya rancangan ini, diharapkan siatem ini dapat memperbaiki kekurangan dan fungsi dari alat monitoring sebelumnya khususnya jika terjadi kerusakan line telepon pada masing-masing line sehingga teknisi tahu masalah yang timbul sebelum ada pihak yang mengeluh dan menghubungi pihak teknisi PABX dan pemecahan masalah itu bisa teratasi dengan cepat dan selesai dengan baik. Jadi dengan terciptanya system monitoring ini. Cara Pembuatan Rancangan ini langkah-langkahnya :

1. Buat desain hardware rancangan alat yang ingin dibuat sesuai dengan konsep rancangan.

2. Etchingkan PCB agar jalur yang sudah didesain bisa digunakan.

3. Solder komponen yang akan dipasang ke PCB sesuai dengan jalur yang sudah tersedia.

4. Uji coba hardware setelah semua komponen tersolder dan terpasang pada PCB.

5. Program Hardware melalui Microcontroller Atmega 16.

6. Program GUI pada PC sebagai monitoring, program GUI disini menggunakan Visual Basic 2008 Express.

Dengan penginstalannya sebagai berikut :

1) Pertama untuk penginstalan Visual Basic

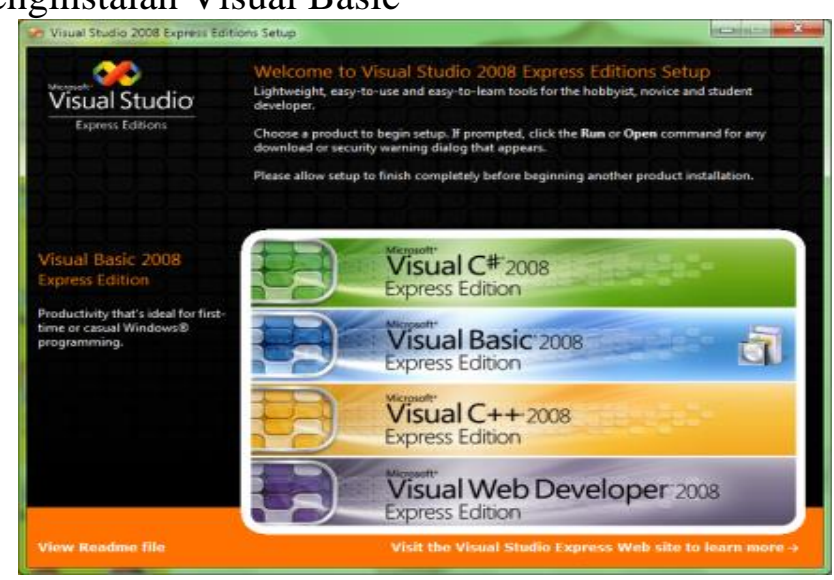

Gambar 9. Tahap pertama penginstalan

2) Kemudian setelah terinstal, setelah itu setting untuk desain monitoring dan juga masukkan Bahasa Pemrograman untuk GUI ini. 


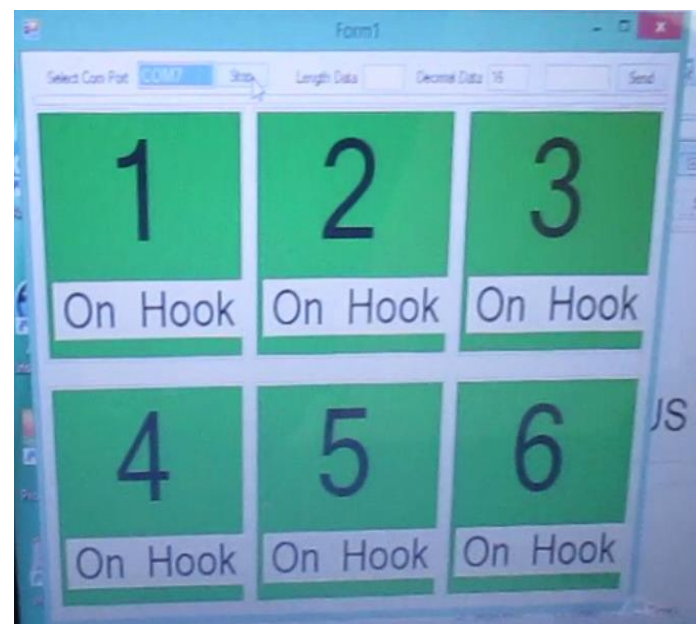

Gambar 10. Tampilan GUI

\section{ANALISA DAN PENGUKURAN}

Pada sistem rancangan yang pertama ini dapat mendeteksi empat macam kondisi dari saluran telephone pada PABX, yaitu On Hook, off Hook, Ringing dan Failure. Berikut adalah rangkaiannya.

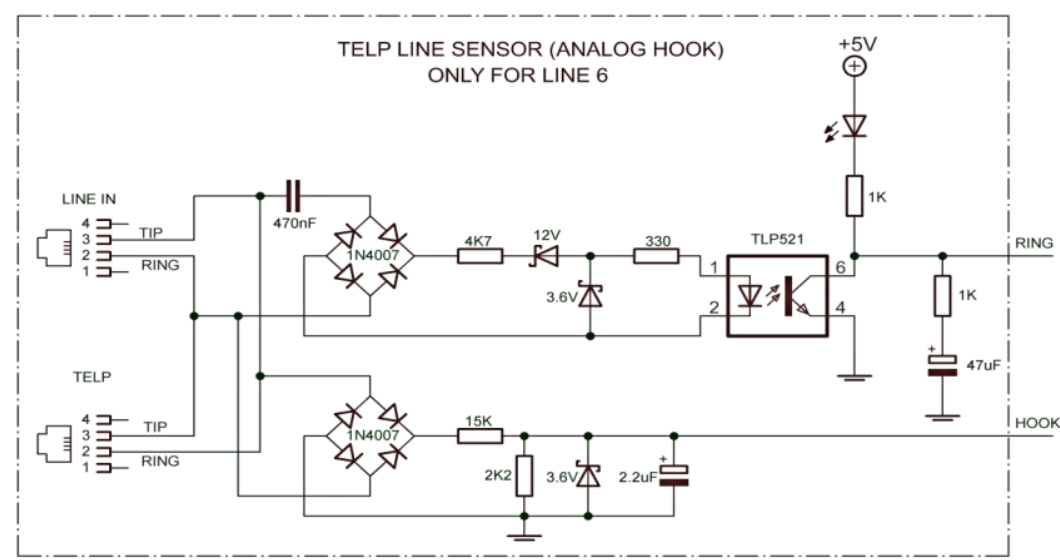

Gambar 11. Rangkaian Sistem Pertama

Pada sistem yang pertama ini cara kerjanya adalah dengan penggunaan sistem kalibrasi tegangan. Dimana sebelum menggunakan rancangan ini, penguji melakukan kalibrasi alat pada saat posisi on hook, dan posisi off hook.

$$
\begin{aligned}
V_{A B} & =V_{(T I P \sim R I N G)}=25 \text { Volt Misalnya } \\
V_{C D} & =V_{(T I P \sim R I N G)}-\left(2 \times V f_{\text {diode }}\right) \\
& =25 \text { Volt }-(2 \times 0,7) \\
& =25 \text { Volt }-1,4 \\
& =23,6 V_{A C}
\end{aligned}
$$

Karena tegangan ringing yang masuk

> 20 Volt, untuk mengantisipasi besar dan kecilnya tegangan ringing yang masuk dari tiap-tiap pesawat telephone yang berbeda-beda besarnya, maka penulis mengambil titik tengah dari range diatas agar resistor yang digunakan tidak terlalu kecil ataupun tidak terlalu besar yaitu sekitar $3 \mathrm{~K} 9$ atau 4K7, sesuai dengan percobaan berikut : 
Tabel 1. Percobaan Penentuan besar resistor pada point CE

\begin{tabular}{|l|l|l|l|}
\hline No. & $\begin{array}{l}\text { Besar } \\
\text { Resistor }\end{array}$ & $\begin{array}{l}\text { I/P dari } \\
\text { Titik C }\end{array}$ & $\begin{array}{l}\text { O/P dari } \\
\text { titik E }\end{array}$ \\
\hline 1 & $2 \mathrm{~K} 2$ & $23,6 \mathrm{~V}$ & $8,070 \mathrm{~V}$ \\
\hline 2 & $3 \mathrm{~K} 9$ & $23,6 \mathrm{~V}$ & $8,099 \mathrm{~V}$ \\
\hline 3 & $4 \mathrm{~K} 7$ & $23,6 \mathrm{~V}$ & $8,108 \mathrm{~V}$ \\
\hline 4 & $10 \mathrm{~K}$ & $23,6 \mathrm{~V}$ & $8,147 \mathrm{~V}$ \\
\hline
\end{tabular}

Dari hasil percobaan beberapa sampel resistor yang digunakan dapat dilihat bahwa selisih tegangan $\mathrm{O} / \mathrm{P}$ yang dihasilkan tidak terlalu besar.

$$
\begin{aligned}
V_{E D} & =V_{\text {zener } 1}+V_{\text {zener } 2}(\text { Seri }) \\
& =12 \text { Volt }+3,6 \text { Volt } \\
& =15,6 \text { Volt } \\
V_{F D} & =V_{\text {zener } 2}=3,6 \text { Volt }
\end{aligned}
$$

Antara TP F \& TP G terdapat resistor sebesar $330 \Omega$ yang juga sebenarnya tidak mutlak sebesar itu, berikut penjelasanya:

Diketahui : $V_{\text {zener } 2}=3,6 \mathrm{~V}$

$V f_{\text {LED opto }}=1,15 \mathrm{~V}$ (Data Sheet)

If $f_{\text {pto }}=10 \mathrm{~mA}$ (DataSheet)

Ditannya: $R=\ldots \ldots \ldots \ldots$ ?

$R=\frac{V_{R}}{I f_{\text {opto }}}=\frac{V_{\text {zener } 2}-V f_{\text {LED opto }}}{10 \mathrm{~mA}}$

$=\frac{3,6 \mathrm{~V}-1,15 \mathrm{~V}}{10 \mathrm{~mA}}$

$=245 \Omega \approx 220 \Omega$ atau $270 \Omega$ atau $330 \Omega$

dalam kasus ini penulis memilih resistor sebesar $330 \Omega$

untuk TP ini

$V_{G D}=V f_{\text {Led opto }}$

$=1,15$ Volt

Transistor yang ada di dalam optocoupler open collector dengan VCC 5 Volt dan disertai rangkaian Low Pass Filter yang berfungsi meneruskan frequency rendah dan menghambat frequency tinggi sebagai pengaman tambahannya.

\section{Kondisi Hook}

Sedangkan pada kondisi Hook terbagi menjadii dua kondisi lagi yaitu On Hook (Gagang Telephone tidak diangkat) dan Off Hook (Gagang Telephone dangkat) dimana tegangan yang masuk langsung disearahkan oleh bridge diode dan kemudian hasil pembacaannya di tampilkan sesuai dari tegangan yang masuk. Seperti pada penjelasan yang telah dijelaskan dalam kondisi ringing untuk logic " 0 " dianggap kondisi ringing, sedang logic " 1 " dianggap kondisi Hook (On Hook maupun Off Hook), berikut perhitungan dari kondisi Hook.

Seperti yang telah dijelaskan di bab dua, untuk pengukuran On Hook adalah $\pm 20 \mathrm{~V}$ sedangkan Off Hook $\pm 8 \mathrm{~V}$ sehingga untuk pembacaan ADC nya penulis memberikan resistansi 2 Volt. 


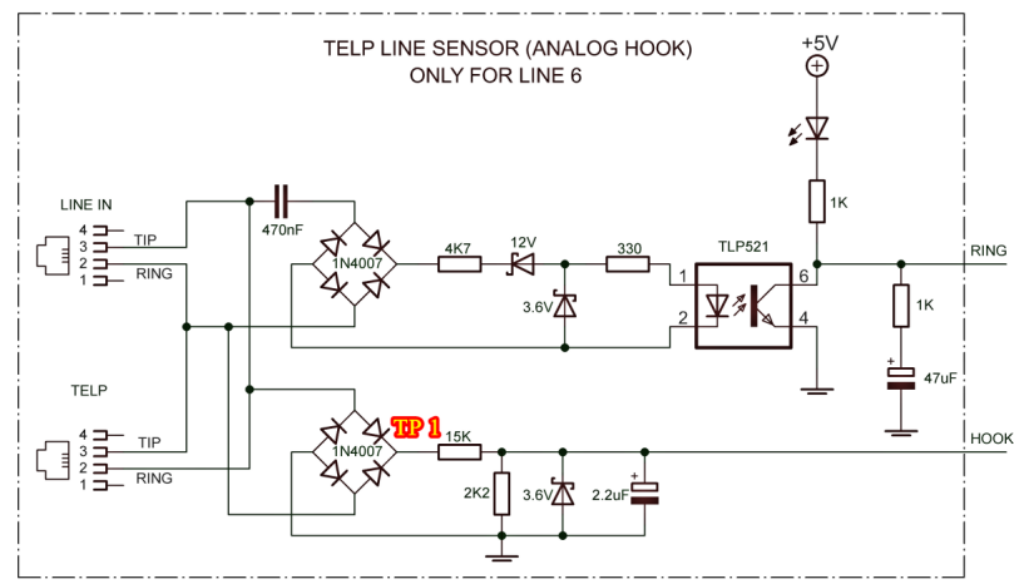

Gambar 12. Test Point Pengukuran kondisi Hook

\section{Kondisi Failure}

Kondisi ini secara perhitungan, karena pada pembacaan ADC untuk kondisi On Hook diberikan 20 Volt dan kondisi Off Hook 8 Volt dengan resistansi 2Volt, maka selain range tegangan tersebut dianggap kondisi Failure.
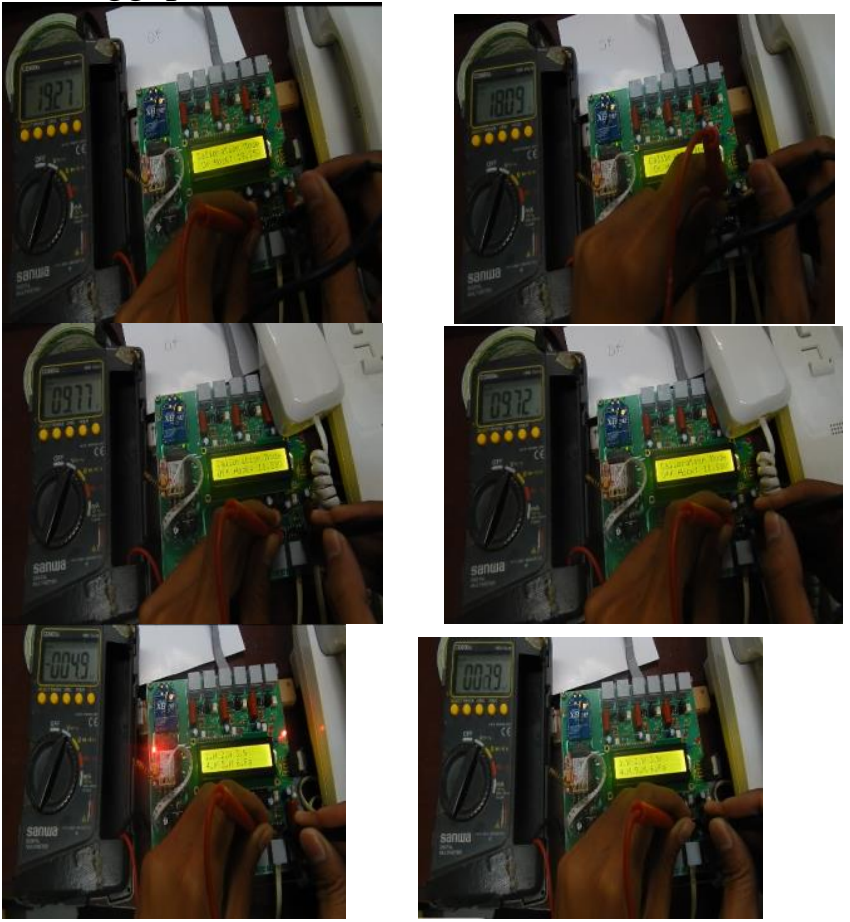

Gambar 13. Percobaan dengan pengukuran

Dari hasil uji coba dan ditulis pada tabel pengamatan diatas dapat ditarik kesimpulan bahwa perbandingan dari percobaan pengukuran dan perhitungan sinkron (tidak berbeda jauh)

\section{KESIMPULAN}

a. Alat indikator ini pada line 1 sampai dengan line 5 dapat digunakan untuk mengetahui kondisi saluran telepon yang ringing (berdering), gagang telephone tidak diangkat (onhook), gagang telephone diangkat (off-hook), serta untuk line 6 dapat digunakan untuk mengetahui kondisi saluran telepon yang ringing (berdering), gagang telephone tidak diangkat (on-hook), gagang telephone diangkat (off-hook), dan kerusakan telepon (Failure). 
b. Dengan menggunakan alat ini maka para teknisi yang bekerja pada unit PABX bisa mengetahui kondisi saluran telepon secara lebih jelas.

\section{DAFTAR PUSTAKA}

Komunikasi Elektronika Edisi ketiga. terjemahan Kamal Idris Penerbit Erlangga, Jakarta 1984

Pemrograman mikrokontroler AVR ATMEGA 16 menggunakan bahasa C ,Code Vision AVR

Aplikasi Database dengan Visual Basic 6.0 untuk Orang Awam, Maxicom, Palembang, 2008. Microsoft Visual Basic 6.0 untuk Pemula, Andi, Madiun, 2008.

Tip \& Trik Pemograman Visual Basic 6.0, Andi, Yogyakarta, 2001. 